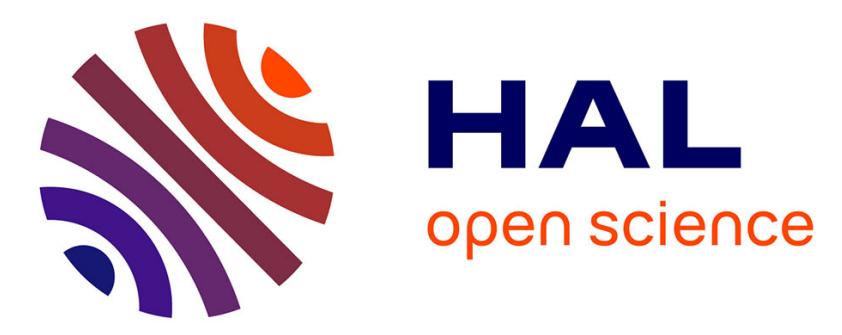

\title{
Introducing Blended Learning MOOC - A Study of One bMOOC in Norwegian Teacher Education
}

\author{
Inger Langseth, Halvdan Haugsbakken
}

\section{To cite this version:}

Inger Langseth, Halvdan Haugsbakken. Introducing Blended Learning MOOC - A Study of One bMOOC in Norwegian Teacher Education. 1st International Conference on Stakeholders and Information Technology in Education (SAITE), Jul 2016, Guimarães, Portugal. pp.59-71, 10.1007/978-3319-54687-2_6. hal-01625390

\section{HAL Id: hal-01625390 \\ https://hal.inria.fr/hal-01625390}

Submitted on 27 Oct 2017

HAL is a multi-disciplinary open access archive for the deposit and dissemination of scientific research documents, whether they are published or not. The documents may come from teaching and research institutions in France or abroad, or from public or private research centers.
L'archive ouverte pluridisciplinaire HAL, est destinée au dépôt et à la diffusion de documents scientifiques de niveau recherche, publiés ou non, émanant des établissements d'enseignement et de recherche français ou étrangers, des laboratoires publics ou privés. 


\title{
Introducing Blended Learning MOOC - A Study of One bMOOC in Norwegian Teacher Education
}

\author{
Inger Langseth $^{1}$ and Halvdan Haugsbakken ${ }^{2}$ \\ ${ }^{1}$ Program for Teacher Education, \\ Norwegian University of Science and Technology, Trondheim, Norway \\ Inger. Langsethentnu.no \\ ${ }^{2}$ Department of Sociology and Political Science, \\ Norwegian University of Science and Technology, Trondheim, Norway \\ Halvdan. Haugsbakkenesvt.ntnu.no
}

\begin{abstract}
Although MOOCs have been around for a decade, the use of MOOCs in teacher training is a new development. In 2015, a Norwegian teacher education received internal funding to develop a MOOC intended for blended learning, which we call bMOOC. The bMOOC consisted of four different modules, and the course content was created internally by highly competent teacher trainers. One goal with the bMOOC was to familiarize teacher students and teacher educators with the concept of blended learning. Another goal was to support students' academic writing processes across courses and possibly take some of the workload connected to instruction and feedback off the teacher trainers. The article analyzes the outcome of the implementation of the bMOOC, which shows low user adoption rate and low course completion. The study questions whether teacher educators see the pedagogical value in MOOCs and whether teacher students have enough digital competence to make use of online learning objects in formal learning.
\end{abstract}

Keywords: Teacher education $\cdot$ blended learning $\cdot \mathrm{MOOC} \cdot$ digital competence.

\section{Introduction}

Our study discusses the introduction of a blended learning MOOC in teacher education, with an emphasis on the relationship between digital learning and teacher education. Although there is broad agreement that developing teacher students' digital competence is important, digital pedagogical innovation occurs primarily in the practice field and rarely in teacher education [1]. Moreover, when teacher students and teacher educators are offered the possibility to use new digital learning objects (DLO), both groups tend to prefer more traditional practices, thereby missing out on the benefits of developing their digital competences. If this is the case, institutional practices in teacher education contribute to a status quo and the reproduction of the technology-practice gap in education, something that the field has been criticized for [2]. One possible consequence of this contradiction is that teacher education will lag further behind schools in the use 
of digital technology for teaching and learning and make goals set in national educational policies difficult to reach. Another peculiarity is that while teacher educators succeed in developing teachers' competencies in schools $[3,4]$, they seem to struggle when developing digital competencies internally, among their own staff.

To illustrate some of the complexity of the challenges above, this paper analyzes the introduction and experiences of a blended learning MOOC (bMOOC) containing several learning objects in four modules. The bMOOC was implemented as an integrated course across subjects in Norwegian teacher education in the fall 2015. Our research question is: What happens when a bMOOC is introduced in teacher education?

To show our argument, we will first define the paper's conceptual framework, by focusing on recent and relevant MOOC research. We will frame what we mean by the bMOOC concept. Second, we will describe our methodological approach, where we outline the research strategies we used to analyze the data we collected in our study. Third, we will present our research findings. Finally, we will draw some conclusions.

\section{A Need to Address Blended Learning in MOOCs}

To frame what we mean with the bMOOC concept in teacher education, we will contextualize the concept in recent developments in the MOOC literature.

In terms of educational philosophies, the interest in MOOCs has developed across two trajectories over the last decade. On the one hand, from 2009, one saw the rise of cMOOCs. The cMOOC is characterized by the introduction of Connectivism and the work of Canadian scholars [5]. Later, the cMOOC was described as connectivist, due to its "loose" design, meaning that there is no standard technology platform, no formal course content and no formal assessment [6]. Learning is interest-driven with an emphasis on social learning and based on networking and discussions among participants on social media. On the other hand, from 2012, a new scholarship, the xMOOC, emerged [5]. Here, the educational philosophy differs, in the sense that learning focuses on transferring pre-defined information from expert to novice. In this sense, xMOOCs are more "behavioristic", involving instruction by means of video lectures, automated feedback and assessment (by peers) [6]. They are intended for global and scalable courses and offer a certificate upon completion. They also offer the possibility of big data analysis. The XMOOC is a development fronted by American elite universities and commercial actors.

There is a vast emerging body of research literature on MOOCs. In brief, the research literature investigates the outcomes of MOOCs that are offered to off-campus students, and develops around particular research streams. Looking at relevant research streams, studies that examine the social background of participants, report the reoccurring finding that students are males who have completed higher education and have an average age around 30 [7]. Furthermore, user demographics show that MOOC courses are U.S. and Europe based and few studies in English show MOOC experiences from African and Asian countries [8,9]. MOOC research papers also examine learner perspectives, focusing on what it means to teach for large online audiences and why MOOCs have low completion and high dropout rates. In some studies, scholars break 
down course populations and analyze different types of user commitment [10]. For example, Milligan et al. [11] classified three different types of participant groups - passive participants, lurkers, and active participants, a categorization indicating levels of student engagement. Many studies report that the dropout rate is at 94 percent on average $[12,13]$, but researchers identify the various reasons why students drop out and suggest strategies to make MOOC courses more sustainable [14]. Researchers attempt to establish the learning outcomes of a MOOC, something that has proven difficult to determine. Particular studies compared MOOC courses in mathematics with a similar oncampus course at an American university and found no significant difference [15]. Other studies show that the MOOC idea of being "large" is itself a challenge for learning. Large classes can lead to information-overload and loss of overview $[16,17]$, something which is also proven in studies on discussion forums [18]. Here, studies recommend some type of online intervention, for example in the form of a moderator that can guide students [19]. Recent studies have explored the idea of gamification [20], which is a method to award students with badges as motivation to complete courses. Here, studies claim that gamification can increase user enrolment and increase user engagement [21, 22].

MOOC is clearly a flexible concept that is under development. According to Bates [6], there seems to be three distinct patterns within the development of MOOC courses: 1) the transfer of best practices from credit-based online courses, like the use of moderated discussion groups, 2) the opening up of regular campus classes to non-registered students and 3) the use of blended learning. Our study elaborates on blended learning and the bMOOC concept in teacher education.

The bMOOC is based on a social and connectivist approach to learning [23], where online and campus-based teaching and learning merge to improve educational outcomes. We suggest a definition of six concepts in order to describe how technology integrates with teaching and learning in bMOOCs in the following educational philosophy:

1) Digital competence building: When online MOOC content is blended with oncampus courses, pedagogical uses of new technologies are modeled, scaffolded and explored. It is of vital importance that teacher students develop their digital competence in formal educational contexts in their pre-service training in order to be able to contribute to the digital competency development in schools when they graduate. Digital literacy is one of several concepts that try to capture what a pedagogical use of technology involves:

The awareness, attitude and ability of individuals to appropriately use digital tools and facilities to identify, access, manage, integrate, evaluate, analyse and synthesise digital resources, construct new knowledge, create media expressions, and communicate with others, in the context of specific life situations, in order to enable constructive social action; and to reflect upon this process. [24]

2) Joint knowledge-construction: bMOOCs facilitate new ways of collaborative teaching and learning in formal education. Teacher educators can co-construct MOOC modules in subject areas that are taught across courses, something which facilitates both content validity and quality and collaborative learning and competence building among 
novices and experts in an area of study. Examples are MOOC modules in academic writing and scientific methods. Likewise, teacher students get constant access to preselected information in multiple modalities (text, video, visuals etc.), and they can share ideas and get timely feedback from a larger group of students and educators in the discussion forums.

3) Time saving design: The bMOOC design is time saving, in the sense that teacher educators can spend less time on content development and more time interacting with students, either online or in class, which according to Bates [6] is important if students are to develop deep understanding, transformative learning, evidence-based critical thinking and high level decision making.

4) Transparency: The design is transparent, in the sense that bMOOC content - information, questions, feedback and user statistics and research data - is shared. The data informs teacher educators about troublesome knowledge, participation rates etc. in the learning processes and makes it possible to modify courses based on research and learning analytics.

5) 21 st Century skills: bMOOCs encompass social elements like collaboration, cooperation, sharing, curating and social media use, which are powerful skills in the 21 st Century.

6) Scalable and social: The bMOOC has its strength in the social fabric that potentially exists in and between the two learning spaces. It is possible to offer high quality information to scalable groups of students in the MOOC and provide scaffolding and feedback to individuals and smaller groups of students in the courses on campus, thus combining best practices from both MOOC technology and campus-based pedagogy.

The bMOOC concept has implications for how new educational practices are implemented in teacher education. The commonly used strategies, where stakeholders are informed by e-mail, in meetings or in a research and development project design, may not serve the purpose. For example, the reflection-on-action approach is typically based on previous experience in a learning context upon which participants are invited to reflect, thereby thinking in new ways, seeing things from other angles and using general theories to see possibilities for change and improvement in their teaching [25]. In new digital surroundings, participants may well be void of previous experiences with new digital teaching and learning to reflect upon. Moreover, due to the speed of the technological development, it is only partially possible to conduct theory informed teaching and learning in new digital contexts. Research says much about what has promoted formal learning, less about what promotes learning in today's and tomorrow's technology informed educational cultures [26]. Consequently, participants in their first bMOOC are exposed to some level of risk taking, and lack of confidence in their own digital competences and resistance to change might impede the learning process.

There is a need for a different approach to research-based education in digital contexts. One possible approach is to base development on reflection-in-action [25], where participants reflect while spending time to learn to master the new technologies and to move out of their own comfort zone and engage in "risk taking" activities that involve collaboration and sharing in one simultaneous action. This implies that reflection takes place in a situation where "all the events, together, are experienced at once, at the same time" [25]. Reflection is then demanded by digital conditions and stimulated by native 
curiosity in an ongoing process, also described in Schön's concept of reflection-in-action as spontaneous, common, real thinking that may make sense to the practitioner. In connectivist terms, learning then happens when patterns gradually emerge from chaos while engaging in a network of nodes [27].

\section{Methods}

Our data analysis is based on a mixed research approach. We used quantitative and qualitative methods. Our data is triangulated to check for reliabilities and valid measurements. This research strategy has consisted of comparing our research findings from our quantitative data analysis with research results from our qualitative data analysis.

Our quantitative research strategy consisted in collecting and analyzing course data from an LMS, which made up the technological platform of the bMOOC. After course completion, we reviewed registered course data on user participation to exclude invalid data. A total of 326 users or cases were registered at the start of the course, but 46 users were excluded from our data analysis, reducing our final data sample to 280, divided into 256 teacher students and 24 teacher trainers. From there, we derived an overview on descriptive statistics on user participation among teacher student and teacher trainers.

Our qualitative research approach consisted of collecting and analyzing data on user participation in the LMS and qualitative interviews with teacher students and teacher educators. The interviewees were randomly selected among volunteers present at one lecture and in one meeting. In total, twelve interviews were completed, six individual interviews with teacher students and six individual interviews with teacher educators. We used a semi-structured interview guide, where we asked a number of simple, short questions; how they learned about the MOOC, whether they accessed the MOOC, how they used the learning objects, and their thoughts on module contents. The interviews lasted from 15 to 30 minutes. The interviews were recorded on a digital audio recorder. Our data was collected from October to December 2015.

After completing the interviews, they were transcribed and translated into English. We used a constant comparative method [28] and open coding strategy to analyze the the data from the interviews. We looked for patterns in our interview data. After coding our data material in several rounds, we arrived at some categories. We grouped the teacher students' and teacher educators' answers into larger categories in an interrelated method, where two researchers worked together. We used direct quotations to give our informants a voice.

The study is based on informed consent. The teacher education and the informants involved in the study have been made anonymous [29]. 


\section{Data Analysis - Presentation Of Research Findings}

We have divided our data analysis into three sections. The first part describes the background and the context for the bMOOC and its overall course content. The second part presents research findings from our quantitative data analysis. The analysis focuses on course data and provides simple descriptive statistics on a number of defined variables, which are meant to highlight online activity or traffic in the bMOOC. The third part focuses on the study's qualitative data. Here, we provide an analysis of user experiences, where we analyze teacher students' and teacher trainers' use and evaluation of the bMOOC, including user experiences of one separate module on academic writing.

\subsection{The Background for Initiating the bMOOC}

The teacher education, which has about 450 teacher students and 70 teacher educators, is located in an urban area and is part of a Norwegian university. During the spring of 2015 , the teacher education received internal funding to develop a blended learning MOOC, where the goal was to improve teaching and learning in higher education. There were several reasons for initiating the blended learning MOOC project. In order to improve the quality of the foundation courses on campus, one aim was to familiarize teacher students and teacher educators with the concept of blended learning. Another aim was to support students' academic writing processes across courses and possibly take some of the workload connected to instruction and feedback off the teacher trainers. The bMOOC was inspired by a "flipped classroom" model and involved the use of multimodal learning objects, student-based activities, sharing, cooperation and collaboration in the learning processes. The bMOOC intended to develop a community of digitally competent teacher educators and teacher students, who in the long term could contribute to changing existing teaching and learning processes in schools in the Norwegian K-12 system.

Looking at the design and the content in the bMOOC, it was intended as an online resource across subjects that teacher students and teacher educators could use throughout the semester, and additionally as a supplement to teacher students' individual competence development. Each of the four modules in the bMOOC intended to scaffold teacher students' key competences in their future professional career as teachers. The bMOOC modules were: how to master the art of academic writing, how to develop a personal learning network (PLN), how to master digital note taking and collaborative writing and the use of digital blackboards. Each module was estimated to 1-3 hours' work online. For example, the academic writing module discussed the pitfalls of academic writing. It consisted of texts, videos, discussions and an evaluation of the module. In addition, there were "reflection tags" indicating where teacher trainers could make use of the course on campus (blending). The module was divided in three sections: 1) an introduction to academic writing, intended to be read once 2) a presentation of the academic text structure, which was intended to be used in the writing process and 3) help when students experience a writer's block, which was specially intended for students who struggle with academic writing. The amount of time each student teacher 
or teacher trainer would spend in the bMOOC depended on previous experience with digital tools and academic writing. Taking the bMOOC was estimated to about 5 hours.

\subsection{Quantitative Data Analysis of the bMOOC}

We stress that our quantitative data analysis is not complete, only preliminary. In general, the analysis suggests that the bMOOC's online activity shares several traits seen in Social Network Sites (SNS) or online communities. For example, it is not uncommon that online communities experience a rapid adoption rate among users, but later have challenges to become sustainable and create active online engagement. This often results in an equal drop-down rate as online communities lose popularity. In our study, we find little data suggesting that teacher students and teacher educators initiate online contact with peers and engage in an online discussion in the bMOOC modules, something that one could expect in our case. There appears to be a small core group of users who have completed the four modules in the bMOOC. In our data set, the bMOOC has a high online activity in September, but this declines as the course progresses.

A pattern emerges when we look at distinct variables, like the teacher student's total time spent online in the bMOOC, as shown in the LMS analytics. When breaking down the mentioned variable on a more detailed level, interesting research findings emerge. We have for example divided the teacher students' online activity into four time subcategories or values. This division shows that 27 percent of the teacher students spent between 0-5 minutes, 41 percent used between 5-60 minutes, 22 percent spent between one to five hours, and 10 percent spent five hours or more. Largely, female teacher students have recorded most online activity. This means that the most expected characteristic user pattern consists of login on and engagement with the course material for an hour or two, before dropping out never to return. The data also demonstrates a "thinning" of number of teacher students, when an increase in recorded online time is considered. Only 22 teacher students have logged more than five hours of online activity.

Analyzing our course data on the teacher educators' use and online engagement, we see a similar user pattern. The teacher educators' total time spent on the bMOOC is somewhat similar to that of the teacher students. Of the 24 teacher trainers, 12.5 percent spent between 0-5 minutes, 37.5 percent used about 5-60 minutes, 37.5 percent recorded 1-5 hours, and 10 percent spent five hours or more on the bMOOC. Our data suggests that the teacher educators exhibit the same user behavior as those they intend to educate; many teacher educators seem to register and take a look at the bMOOC but never return to work with the online material.

Our initial observations are confirmed in other variables in our data set. Another way to conceptualize online activity is to look at the variable page views. Page views is a variable indicating how many times a web page in the bMOOC has been loaded. Descriptive statistics from the LMS analytics used to organize the bMOOC show that there were 4314 page views in September, 2239 in October, 641 in November, and 91 in December. Here, we can also observe a progressive decline in online activity, where the peak starts in September and follows a steady drop, as the bMOOC progresses. 


\subsection{Qualitative Data Analysis of the bMOOC}

The qualitative data also confirms user experiences and online patterns established in our preliminary quantitative data analysis. Our qualitative data is only preliminary.

In our interviews, we explored the teacher students' user experiences. One surprising research finding was the teacher students' view on the value of online learning and the bMOOC. Some teacher students stated that online learning and the use of digital resources bring little benefit, and that they prefer other approaches to learning. This suggests a contradictory view on technology in education. On the one hand, teacher students are brought up in a digital world, but on the other hand, they approach and frame digital learning from a textbook perspective. Our data suggests that the teacher students are inexperienced with online learning and the demanding work it involves.

Data collected from the LMS confirms the above pattern. The course data shows that the teacher students did not actively participate in the academic writing module in the bMOOC. Course data from the module establishes that there are few online discussion entries, comments and replies.

The teacher students' low and passive online participation is utterly elaborated on in the evaluation of the academic writing module. Five of the seven teacher students who evaluated the module were women. Five of them reported that they took the whole module, while one took about half and one took selected elements. The respondents said that the module was useful to them, referring to different elements in the module. They were most positive about the middle section made for the more hands-on writing process, but all the three sections were considered relevant to them. They report that they to some extent understood more about the writing process after taking the bMOOC. The data shows that there was no collaboration in the discussion forums, even though they reported that they were willing to collaborate online with other participants.

In the online evaluation, student teachers reported that they had not been properly informed about the bMOOC. In the interviews, the teacher educators reported that only a few students were present when the bMOOC was introduced. Moreover, the presentation was optional. Six of the seven teacher students reported that their teacher educator had briefly informed them about the academic writing module, meaning that they never used the bMOOC actively in the course.

In the interviews, the teacher students reported that working in the bMOOC was too time-consuming. Consequently, the online material in the bMOOC was considered of little relevance to their exams in academic writing and learning. They preferred other approaches, like traditional feedback from the tutor and peer assessment on campus. This female teacher student favored writing an academic text on paper by herself, completing it the "old fashion way, in order to save time and get on with other things":

I opened the MOOC and no, can't be bothered. It will take less time to just write the text yourself. Surely, a good thing, but it takes more time than you will get back from doing it, and you must read it, that is time better spent on writing the academic text itself or doing other things.

The interviews show that the teacher students had varying approaches and prior experiences with academic writing. In the module evaluation, two of seven teacher students reported that they had only been taught to write in secondary school, whereas five had 
been instructed in academic writing in higher education in previous courses. This finding is elaborated on in the interviews, where teacher students commented upon the relevance of a bMOOC in formal learning in academic writing

We asked the teacher students to explain how they learned to write academic texts. They suggested different methodological approaches involving help from peers and tutors on campus, but very few saw the value of online collaborative learning:

We get feedback on the first draft. Some teacher trainers have given very concrete feedback that helps. Students can also give peer reviews. That is not in all subjects, but in many. I think it helps, I get new perspectives and new ways of forming sentences. It is also scary. If it is good, I am afraid that the other students will steal my idea, if I think it is a bad text, it is a bit awkward.

The teacher educators' user experiences are different from those they are set to train as future teachers. The teacher educators saw and emphasized the potentially positive educational benefits with MOOCs, but this is contradicted in practice. A theme running through our interviews was the lack of information about the bMOOC itself. Six teacher educators explained that they had to a variable extent received information about the bMOOC and how to sign up for it. For example, they had challenges in remembering where to find URL links, which would enable them to login in to the bMOOC.

The teacher educators have a dual relationship with the bMOOC concept. On the one hand, they acknowledge the importance of the digital learning environment. On the other hand, they prefer the social and relational aspect on campus. This applies especially to feedback on teacher students' academic text production. For example:

I think the f-2-f-relation we have with our students is important. I think direct contact with me is more important, and therefore we used the MOOC on 2nd year students. I believe these online resources can make our work on feedback easier. We have high scores on student evaluations, and that is because we spend a lot of time on relations.

The teacher educators underlined that the bMOOC could have a positive impact on the amount of time they spend giving feedback to the teacher students. Here, they saw the MOOC as a positive contribution to students' writing process and a valuable resource in their work:

I use a lot, lot of time to give feedback on students' academic texts. It takes time to give many students feedback with notes: You need more references, you need to include theory before the end, you need to structure your text etc. My God, I spend a lot of time giving feedback. I spent two hours on one text today. Later in the studies, it is easier. I spend some 1-2 hours per text. Students have asked for help online. I see that we need to give more information about academic writing.

Finally, the teacher trainers emphasized that the success and impact of a bMOOC, depends upon certain organizational factors. Like any new practice introduced into an education system, the bMOOC must have legitimacy and support from the teaching institution. For example, when a bMOOC is implemented, it needs the support from the top-management. Suitable routines to inform all stakeholders must be established, so that potential users are aware of the existence of the bMOOC. In other words, the 
teacher trainers emphasized the need for better management strategies in the implementation of the bMOOC.

\section{Discussion and Conclusion}

Initially, we asked what happens when a bMOOC is introduced in teacher education. Our study tries to answer the research question by raising some questions that we wish to discuss, and that we believe might contribute to the research on MOOCs in teaching and learning. First, our research confirms previous research findings on social media and MOOCs. On the one hand, several studies have pointed out that many MOOCs have a low completion rate, with an estimated dropout rate of 94 per cent $[16,17]$. Therefore, our data analysis appears only to confirm previous studies. On the other hand, there is a tendency in educational research on social media, for example, to question whether today's adolescents are truly "digital natives" [30]. Some scholars have hinted that this is an ascribed myth that needs to be challenged. Various scholars point out both in studies [31,32] and research reviews [33-35] that students in higher education might have a digital upbringing, but they seldom live up to expected standards defined in formal, digital learning. Rather, adolescents appear to be passive consumers of digital content and frame the educational online world from a textbook oriented approach. We see evidence of this in our analysis. The majority of teacher students and teacher trainers are inexperienced with formally structured online learning and seem to perceive the bMOOC as only vaguely beneficial to education and learning.

Second, as an extension of the above, we believe that our study brings interesting nuances as to how teacher students reflect upon how to develop their academic competences. Two features related to "reflection-on-action" [25] emerge in our study: that of time and effort. In a situation where teacher students have limited experiences with formal learning in digital surroundings, their reflection on how to improve their academic writing seems to exclude MOOCs. They also report that the time and effort they choose to spend on their academic papers is in line with the results they assume that they will obtain. Consequently, they conclude that there is no need to look deeper into yet another learning object in the bMOOC. Theoretically speaking, they experience a balance in the situation where they carry out the assignment [25]. From this follows that 1) extending teacher students campus based artefacts to also include online MOOCs seems to be too much of an effort. Our study shows that they enter the MOOC, spend a limited amount of time and leave, never to come back. 2) Behind our findings related to the low adoption rate of the bMOOC, we also find that teacher students' reflection on their own competence development seems to a large extent to be related to personal goals to reduce study hours. 3) Our study also reveals that when confronted with an academic writing assignment, teacher students prefer the" trial and error" strategy to theory informed and research based strategies in the bMOOC. At the same time, teacher educators report that teacher students to a variable extent make use of feedback from educators in their writing processes on campus. These findings suggest a gap between student teachers' perceived and actual competence in academic writing and a lack of strategies to close it. Contrary to this trend, we find another pattern. 4) Among the few teacher students who have made use of the bMOOC, they report to a large 
extent that they find academic writing hard work, and that the bMOOC is worth the effort when completing the academic writing assignment. Our findings suggest that these students have made their reflection-on-action based on previous experiences with online learning and a realistic assessment of their own academic writing skills. Summing up, when deciding what actions to take, teacher students seem to consider whether the bMOOC is worth the time and effort based on previous experiences with online learning and perceived level of confidence in their own academic writing. In previous studies, Dysthe [36], for example, found that Norwegian students had a form of "resistance" towards obligatory activities that were not graded, and that students invested the least possible effort to pass requirements set by their teachers. Our study extends Dysthe's findings to digital surroundings and graded assignments. In the interviews, the teacher educators state that students' competence in academic writing needs to be developed and that they spend a lot of time giving basic feedback on features that, we argue, could have been learned in the bMOOC.

Third, this pattern of beliefs and behavior reproduces the theory-practice gap that we initially described, and the pattern is strengthened when the implementation strategy in the institution is not adequate. We suggest that introducing MOOCs in formal education needs to be more organized and emphasized through active participation in "reflectionin-action" [25]. In order for teacher students to reflect upon the value of online learning, like in the bMOOC, they must be introduced to it on campus, by teacher educators who make advantage of the benefits of social networking and multimedia learning objects. This presupposes that teacher educators are familiar with the MOOC concept. If this is not the case, like our research findings suggest, the possibility of extending the students' learning context to involve online learning and collaboration can be lost. The question that needs to be asked is how to implement digital competence in teacher education. We suggest that the more traditional approach that involves reflection-on-action is not adequate, since it is based on a limited set of digital knowledge and skills. Reflection will then not lead to creativity and invention, which is necessary for change. We suggest that new technologies be introduced in a blended learning approach, where teacher educators jointly are allocated time to develop their digital competence. Two of the participants in our study, who had previously participated in a bMOOC, reported on results that affected their teaching, learning and assessment strategies on campus.

Fourth, as with any research, our study has limitations that have to be acknowledged at this point. This case study contains data that is to a limited extent generalizable to other educational contexts. Other studies can attain other research results. We believe however that our research findings might contribute to a better understanding of the challenges connected to implementing blended learning in educational cultures. Another limitation is that this study is only preliminary. In addition, we did not conduct any research in the classrooms or campus lectures.

The goal of this paper has been to introduce the bMOOC concept into current research on MOOCs and push the field in a new direction. Our study suggests that teacher education has work to do to enhance future teacher students and teacher teachers' digital competences. If the technology-practice gap is not addressed, we are afraid that we can see a widening of this gap in our K-12 education system. 


\section{References}

1. Haugsbakken, H.: Using Social Media The Inside Out; A Aualitative Study of Four Different Local Models for Organizing Social Media in Organizations. NTNU, Trondheim (2016)

2. Irgens, E.J.: Rom for Arbeid: Lederen som Konstruktør av Den Gode Skole. In: Kompetent Skoleledelse. Andreassen, R.A., Irgens, E.J., Skaalvik, E.M. Tapir, Trondheim. pp. 125$145,(2010)$

3. Postholm, M.B.: Teachers Developing Practice: Reflection as Key Activity. Teaching and Teacher Education. International Journal of Research and Studies. 24(7), 1717-1728 (2008)

4. Riksaasen, R., Langseth, I.: Endringer av Praksis i Klasserommet. En Artikkelsamling om Utviklingsarbeid, Aamarbeid, Erfaringer og Forskning. Akademika Forlag, Trondheim (2014)

5. Ebben, M., Murphy, J.S.: Unpacking MOOC Scholarly Discourse: A Review of Nascent MOOC Scholarship. Learning, Media and Technology. 39(3), 328-345 (2014)

6. Bates, T.: Teaching In a Aigital Age. University of British Columbia, (2016)

7. Ho, A.D., Chuang, I., Reich, J., Coleman, C.A., Whitehill, J., Northcutt, C.G., Williams, J.J., Hansen, J.D., Lopez, G., Petersen, R.:, HarvardX and MITx: The First Year of Open Online Courses. In: HarvardX and MITx Working Paper, No. 1. (2014)

8. de Waard, I., Abajian, S., Gallagher, M..S., Hogue, R., Keskin, N., Koutropoulos, A., Osvaldo, R.C.: Using mLearning and MOOCs to Understand Chaos, Emergence, and Complexity in Education. The International Review of Research in Open and Distance Learning, Special Issue-Connectivism: Design and Delivery of Social Networked Learning. 12(7), 94$115(2011)$

9. Kop, R.: The Challenges to Connectivist Learning on Open Online Networks: Learning Experiences During a Massive Open Online Course. The International Review of Research in Open and Distance Learning. Special Issue-Connectivism: Design and Delivery of Social Networked Learning. 12(3) (2011)

10. Anderson, A., Huttenlocher, D., Kleinberg, J., Leskovec, J.: Engaging with Massive Online Courses. In: WWW 2014 - Proceedings of the 23rd International Conference on World Wide Web, Seoul, Korea. ACM. New York (2014)

11. Milligan, C., Littlejohn, A., Margaryan, A.: Patterns of Engagement in Connectivist MOOCs. Merlot Journal of Online Learning and Teaching. 9(2), (2013)

12. Koutropoulos, A., Gallagher, M.S., Abajian, S.C., de Waard, I., Hogue, R.J., Keskin, N. O., Rodriguez, C.O.: Emotive Vocabulary in MOOCs: Context \& Participant Retention. European Journal of Open, Distance and E-Learning. No 1, (2012)

13. Jordan, K.: Initial Trends in Enrolment and Completion of Massive Open Online courses. International Review of Research in Open and Distance Learning. 15(1), 133-160 (2014)

14. Gomez-Zermeno, M.G., Aleman De La Garza, L.: Research Analysis on Mooc Course Dropout and Retention Rates. Turkish Online Journal of Distance Education. 17(2), 3-14 (2016)

15. Colvin, K., Champaign, J., Liu, A., Zhou, Q., Fredericks, C., Pritchard, D.E.: Learning an Introductory Physics MOOC: All Cohorts Learn Equally. International Review of Research in Open and Distributed Learning. 15(4), (2014)

16. Liyanagunawardena, T.R., Adams, A.A., Williams, S.A.: MOOCs: A Systematic Study of the Published Literature 2008-2012. International Review of Research in Open and Distance Learning. 14(3) 202-227 (2013)

17. Knox, J.: Digital Culture Clash: 'Massive' Education in the e-Learning and Digital Cultures. Distance Education. 35(2), (2014)

18. Firmin, R., Schiorring, E., Whitmer, J., Willett, T. Collins, E.D., Sujitparapitaya, S.: Case Study: Using MOOCs for Conventional College Coursework. Distance Education. 35(2), (2014) 
19. Dillenbourg, P.: MOOCs: Two Years Later. In: Research Workshop (Keynote no Printed Record Available), EDEN, Oxford, UK (2014)

20. Crisp, G.T.: Assessment in Next Generation Learning Spaces. International Perspectives on Higher Education Research. 85-100, (2014)

21. Vaibhav, A., Gupta, P.: Gamification of MOOCs for Increasing User Engagement. In: Proceedings of the 2014 IEEE International Conference on MOOCs, Innovation and Technology in Education, Thapar University, Patiala, Punjab, India. IEEE MITE (2014)

22. Chang, J.W, Wei, H.Y.: Exploring Engaging Gamification Mechanics in Massive Online Open Courses. Educational Technology and Society, 19(2), 177-203 (2016)

23. Siemens, G.: Connectivism: A Learning Theory for the Digital Age. International Journal of Instructional Technology and Distance Learning, 2(1) (2005)

24. Martin, A.: Digital Literacy Needed in an "e-permeated" World-Progress Report of DigEulit Project, http://www.idunn.no/ts/dk/2006/02/. (2006)

25. Clarà, M.: What is Reflection? Looking for Clarity in an Ambiguous Notion. Journal of Teacher Education. 66(3), 261-271 (2015)

26. Biesta, G.: Reclaiming a Language for Education in an Age for Learning. Nordisk Pedagogikk. (24), 70-82 (2004)

27. Siemens, G.: Knowing Knowledge: The leadership Perspective Key Note 12. November, Skolelederkonferansen, Lillestrøm, Norway. (2010)

28. Strauss, A., Corbin, J.: Basics of Qualitative Research: Techniques and Procedures for Developing Grounded Theory. Thousand Oaks, CA: Sage Publications, Inc. (1998)

29. NESH. Forskningsetiske Retningslinjer for Samfunnsvitenskap, Jus og Humaniora [Research EthicalGuidelines for Social Science, Law and the Humanities]. Available from: http://www.etikkom.no/no/Vart-arbeid/Hvem-er-vi/Komitefor-samfunnsvitenskap-og-humaniora/ (2006)

30. Prensky, M.: Digital Natives, Digital Immigrants. On the Horizon. 9(5), 1-6 (2001)

31. Junco, R.: The Relationship Between Frequency of Facebook Use, Participation in Facebook Activities, and Student Engagement. Computers and Education. 58(1), 162-171 (2012)

32. Selwyn, N.: Faceworking: Exploring Students' Education-Related Use of Facebook. Learning, Media and Technology. 34(2), 157-174 (2009)

33. Aydin, S.: A Review of Research on Facebook as an Educational Environment. Educational Technology Research and Development. 60(6), 1093-1106 (2012)

34. Hew, K.F.: Students' and Teachers' Use of Facebook. Computers in Human Behavior. 27(2), 662-676, (2011)

35. Manca, S., Ranieri, M.: Is it a Tool Suitable for Learning? A Critical Review of the Literature on Facebook as a Technology-Enhanced Learning Environment. Journal of Computer Assisted Learning. 29(6), 487-504 (2013)

36. Dysthe, O.: Pedagogiske Endringer etter Kvalitetsreforma og Konsekvensar for Læring. Utfordringar og Strategiar Videre. Uniped, 30(3), 29-44 (2007) 